\title{
MS-275 induces hepatic FGF21 expression via H3K18ac-mediated CREBH signal
}

\author{
Qi Zhang1,*, Qin Zhu2,*, Ruyuan Deng3,*, Feiye Zhou², Linlin Zhang², Shushu Wang2, Kecheng Zhu², Xiao Wang², \\ Libin Zhou' ${ }^{2}$ and Qing Su${ }^{1}$ \\ 1Department of Endocrinology, Xinhua Hospital, Shanghai Jiaotong University School of Medicine, Shanghai, China \\ 2Department of Endocrine and Metabolic Diseases, Shanghai Institute of Endocrine and Metabolic Diseases, Shanghai Clinical Center for Endocrine and \\ Metabolic Diseases, Ruijin Hospital, Shanghai Jiaotong University School of Medicine, Shanghai, China \\ ${ }^{3}$ Department of Gastroenterology and Hepatology, Shanghai Institute of Liver Disease, Zhongshan Hospital, Fudan University, Shanghai, China
}

Correspondence should be addressed to L Zhou or Q Su: libinzhou99@hotmail.com or suqing@xinhuamed.com.cn

*(Q Zhang, Q Zhu and R Deng contributed equally to this work)

\begin{abstract}
Fibroblast growth factor 21 (FGF21) plays an important role in the regulation of lipid and glucose metabolism. MS-275, as a class I-specific histone deacetylase (HDAC) inhibitor, has also been reported to affect energy metabolism. In this current study, we investigated the effects of MS-275 on hepatic FGF21 expression in vitro and in vivo and explored whether cAMP-responsive element-binding protein $\mathrm{H}$ (CREBH) was involved in the action of MS-275. Our results showed that MS-275 stimulated hepatic FGF21 mRNA and protein expressions in a dose- and time-dependent manner, as well as FGF21 secretion in primary mouse hepatocytes. Serum concentration and hepatic expression of FGF21 were elevated after injection of MS-275, along with increased expressions of genes involved in fatty acid oxidation and ketogenic production (peroxisome proliferator-activated receptor gammacoactivator $1 \alpha$, PGC-1 $\alpha$; carnitine palmitoyl-transferase 1a, CPT1a; 3-hydroxy-3methylglutaryl-CoA synthase $2, \mathrm{Hmgcs} 2$ ) as well as improved blood lipid profile. As a proved transcription factor of FGF21, the expression of CREBH was initiated by MS-275, with increased histone $\mathrm{H} 3$ lysine 18 acetylation (H3K18ac) signals and hepatocyte nuclear factor 4 alpha (HNF-4 $\alpha$ ) recruitment in CREBH promoter. Adenovirus-mediated knockdown of CREBH abolished MS-275-induced hepatic FGF21 and lipid metabolismrelated gene expressions. These results suggest that MS-275 induces hepatic FGF21 by H3K18ac-mediated CREBH expression.
\end{abstract}

\section{Key Words}

- MS-275

- hepatic FGF21

- H3K18ac

- CREBH

\section{Introduction}

Fibroblast growth factors (FGFs) superfamily has 22 members with diverse biological functions, such as morphogenesis, development, angiogenesis, hematopoiesis, survival and metabolism (Itoh \& Ornitz 2004, Kharitonenkov 2009, Guillemot \& Zimmer 2011). FGF21 is a hormone-like protein expressed in liver, pancreas, adipose, ileum and muscle tissues
(Nishimura et al. 2000, Izumiya et al. 2008, Muise et al. 2008, Yi et al. 2013). In adult mouse, FGF21 is preferentially expressed in the liver (Nishimura et al. 2000). It has been demonstrated that FGF21 administration alleviates hyperglycemia, hyperlipidemia, fatty liver diseases and insulin resistance in obese mice or diabetic monkeys, with body weight reduction (Kharitonenkov et al. 2007, 
Coskun et al. 2008, Xu et al. 2009, Sarruf et al. 2010). FGF21-knockout mice fed with a ketogenic diet developed fatty liver, with body weight gain (Badman et al. 2009). Fasting-induced hepatic FGF21 increases fatty acid oxidation and ketogenesis through the induction of peroxisome proliferator-activated receptor $\gamma$ coactivator protein- $1 \alpha$ (PGC- $1 \alpha)$ to provide the brain with ketone bodies as energy fuels during severe carbohydrate deficit (Potthoff et al. 2009). Therefore, as a metabolic regulator, FGF21 exhibits potential characteristics necessary for the treatment of metabolic diseases, such as obesity, fatty liver and diabetes (Kharitonenkov et al. 2005, Fisher et al. 2011).

Accumulating evidence demonstrates that epigenetics is tightly linked to energy metabolism. Histone deacetylases (HDACs) are regarded as key epigenetic regulators involved in metabolic homeostasis in normal and pathologic conditions (Ferrari et al. 2012, Pham \& Lee 2012). Treatment of db/db mice with MS-275, a class I-specific HDAC inhibitor, resulted in increased glucose tolerance, insulin sensitivity and clearance of liver lipids, as well as decreased plasma triglycerides and free fatty acids (Galmozzi et al. 2013). In diet-induced obese mice, MS-275 treatment showed the same effect, with improved glucose tolerance and metabolic profile (Ferrari et al. 2017). These results highlight the pivotal role of MS-275 in the regulation of energy homeostasis. Interestingly, the beneficial metabolic effect of MS-275 is similar to that of FGF21.

In this current study, we found that MS-275-stimulated FGF21 expression and secretion in mouse hepatocytes in vivo and in vitro, with increased expression of cAMPresponsive element-binding protein $\mathrm{H}(\mathrm{CREBH})$, a liverspecific transcriptional factor. Knockdown of CREBH abolished MS-275-induced hepatic FGF21 expression, suggesting that MS-275 exerts its metabolic action via activating CREBH-induced FGF21 expression.

\section{Materials and methods}

\section{Reagents}

MS-275 (Entinostat) was purchased from Selleckchem (Munich, Germany). Anti-FGF21 antibody, anti-histone H3 (acetyl K18) antibody-ChIP grade and anti-HNF$4 \alpha$ antibody-ChIP grade were purchased from Abcam. Acetyl-histone H3 (Lys9) antibody, acetyl-histone H3 (Lys18) antibody and acetyl-histone H3 (Lys27) antibody were obtained from PTM Biolabs (Hangzhou, China). HSP90 antibody was purchased from Millipore (Billerica).
Histone H3 antibody, acetyl-histone H3 antibody, ribosomal protein S6 kinase (S6K) antibody, ribosomal protein S6 (S6) antibody, phospho-S6K antibody and phospho-S6 antibody were purchased from Cell Signaling Technology. Dulbecco's modified Eagle's medium (DMEM) was obtained from Gibco Life Technologies. Hepatocyte medium (HM) was purchased from ScienCell (Carlsbad, CA, USA). Bovine serum albumin (BSA) was acquired from Sigma.

\section{Animal experiments}

All animal protocols were reviewed and approved by the Animal Care Committee of Ruijin Hospital, Shanghai Jiaotong University School of Medicine. C57BL/6 male mice aged 8-12 weeks (18-20g) were purchased from Shanghai Slack Experimental Center (Shanghai, China) and were housed in a specific pathogen-free environment $\left(24-26^{\circ} \mathrm{C}\right.$, relative humidity $\left.50-60 \%\right)$ with a $12 \mathrm{~h}$ light/ dark cycle and free access to food and water. Ten mice at each time point were randomly assigned to control and MS-275 treatment groups. MS-275 was delivered by intraperitoneal injections in C57BL/6 mice at the dosage of $20 \mathrm{mg} / \mathrm{kg}$ body weight. Blood and tissue samples were stored at $-80^{\circ} \mathrm{C}$.

\section{Primary hepatocytes isolation and cell culture}

Primary mouse hepatocytes were isolated from C57BL/6 mice by a two-step perfusion technique. Hepatocytes were plated onto 6-well, 12-well plates or $10 \mathrm{~cm}$ cell culture dishes and grown in $\mathrm{HM}$ at $37^{\circ} \mathrm{C}$ in $5 \% \mathrm{CO}_{2}$ incubator for overnight. When the cells had attached to the plates, the culture medium was changed from HM to DMEM containing $5.0 \mathrm{mmol} / \mathrm{L}$ glucose, $1.0 \%$ BSA, $100 \mathrm{U} / \mathrm{mL}$ penicillin $\mathrm{G}$ sodium and $100 \mathrm{mg} / \mathrm{mL}$ streptomycin sulfate. After serum starvation, cells were treated with MS-275 for the extraction of RNA or protein.

\section{Quantitative real-time PCR}

Total RNA was extracted from isolated primary mouse hepatocytes and mice livers with TRIzol reagent (Invitrogen, Thermo Fisher Scientific, Inc.) according to the manufacturer's protocol and used for reverse transcription with MMLV-reverse transcriptase (Promega) and oligo (T) primer. Quantitative real-time PCR (qRT-PCR) amplification and detection were performed using a SYBR Premix Ex Taq (Takara) on a Light-Cycler 480 instrument (Roche Applied Science). The results of 
Table 1 Sequence of the primers used for qRT-PCR.

\begin{tabular}{l} 
Gene \\
\hline$\beta$-Actin \\
$18 S$ \\
FGF21 \\
PPAR- $\alpha$ \\
PPAR- $\gamma$ \\
nur77 \\
ATF4 \\
STAT5 \\
CREBH \\
FXR \\
AHR \\
CHREBP \\
SIRT1 \\
ATF6 \\
PGC-1 $\alpha$ \\
CPT1a \\
HIIICS2
\end{tabular}

\begin{tabular}{ll}
\hline \multicolumn{1}{c}{ Primer sequence $^{\prime}$} & \multicolumn{2}{c}{ Reverse } \\
\cline { 2 - 2 } Forward & 5'-CCAGTTGGTAACAATGCCATGT-3' \\
\hline 5'-GGCTGTATTCCCCTCCATCG-3' & 5'-GCCTCAGTTCCGAAAACCA-3' \\
5'-ACCGCAGCTAGGAATAATGGA-3' & 5'-ACACATTGTAACCGTCCTCCAGCAG-3' \\
5'-GGGGTCATTCAAATCCTGGGTGTCA-3' & 5'-ACTCGCGTGTGATAAAGCCA-3' \\
5'-AGAGGCAGAGGTCCGATTCT-3' & 5'-GGCATTGTGAGACATCCCCA-3' \\
5'-ATTGAGTGCCGAGTCTGTGG-3' & 5'-GAAGAAGACGTGGAGGAGGC-3' \\
5'-GAGTTCGGCAAGCCTACCAT-3' & 5'-GGTCATAAGGTTTGGGCCGA-3' \\
5'-GCCTGACTCTGCTGCTTACA-3' & 5'-GGTGGTTGCTGCTGATGTTG-3' \\
5'-GCCAGGACCACAATGCTACT-3' & 5'-TGGAGGGGAGGATGATCAGG-3' \\
5'-GAACCGGATGTCAGCGTGTA-3' & 5'-ACTTTAGCCAGCCACCATCC-3' \\
5'-TCCACGAAGACTCCCTCACA-3' & 5'-GCTGACGCTGAGCCTAAGAA-3' \\
5'-AACAGTAAAGCCCATCCCCG-3' & 5'-ATCTTGGTCTTAGGGTCTTCAGG-3' \\
5'-CACTCAGGGAATACACGCCTAC-3' & 5'-GGCGTGGAGGTTTTCAGTA-3' \\
5'-AGGGAACCTTTGCCTCATCT-3' & 5'-TCCAGGGGAGGCGTAATACA-3' \\
5'-CATGAACTTCGAGGCTGGGT-3' & 5'-CTCAAGAGCAGCGAAAGCGTCACAG-3' \\
5'-ATACCGCAAAGAGCACGAGAAG-3' & 5'-GGTGGCCATGACATACTCCC-3' \\
5'-TTGGACGAATCGGAACAGGG-3' & 5'-ATTGAAGAGGGAGGCTGTGC-3' \\
5'-GGCTGATGGAACGCACAAAG-3' & \\
\hline
\end{tabular}

relative expression were normalized to $\beta$-actin/18S mRNA levels in each sample. The primer sequences used for qRT-PCR were as follows in Table 1.

\section{Western blot}

Primary mouse hepatocytes were washed twice with ice-cold phosphate-buffered saline (PBS) and placed immediately in lysis buffer containing $1 \mathrm{mmol} / \mathrm{L}$ phenylmethylsulfonyl fluoride (PMSF), phosphatase inhibitor cocktail V (Merck) and protease inhibitor cocktail I (Millipore). Lysates were then mixed and centrifuged at $4^{\circ} \mathrm{C}$. Histones of primary mouse hepatocytes and mice livers were extracted using EpiQuid Total Histone Extraction Kit (Epigentek, Brooklyn, NY, USA). The protein concentration of the extracts was quantified by BCA protein assay (Pierce). Protein samples were separated by electrophoresis on $10 \%$ polyacrylamide gels and transferred to a PVDF membrane (Bio-Rad). The blotted membrane was imaged with a LAS-4000 Super CCD Remote Control Science Imaging System (Fuji, JAP).

\section{Adenovirus infection}

Adenovirus vectors containing CREBH-shRNA and control shRNA were synthesized by GeneChem Co., Ltd. (Shanghai, China). The STEM nucleotide sequence for the shRNA against CREBH (shCREBH) was designed as follows: GAGCAGAAAGTTCTACTAAAT. Primary mouse hepatocytes were infected with adenoviruses for $24 \mathrm{~h}$ according to the manufacturer's instruction. Infected mouse hepatocytes were then used for subsequent experiments.

\section{Chromatin immunoprecipitation sequencing (ChIP-seq) and ChIP-qPCR validation}

The sample preparations were performed based on the manufacturer's protocols. Briefly, after $8 \mathrm{~h}$ treatment of MS-275, primary mouse hepatocytes $\left(1 \times 10^{7}\right)$ were cross-linked with $37 \%$ formaldehyde for $10 \mathrm{~min}$ at room temperature and the reaction was quenched with $125 \mathrm{mM}$ glycine, then washed with ice-cold PBS and harvested. The ChIP-seq analysis was performed by KangChen Bio-tech Inc. Corporations (Shanghai, China).

For ChIP-qPCR validation, the soluble chromatin was subjected to immunoprecipitation with anti-H3K18ac antibody and anti-HNF- $4 \alpha$ antibody. Precipitated DNA was amplified by qRT-PCR using primers specific for the CREBH promoter segments. Each cycle threshold (CT) value was normalized to the percentage of input DNA by using IP/INPUT. The primer sequences used for ChIP-qPCR were as follows in Table 2. The primer used in ChIP-qPCR with anti-H3K18ac antibody was designed according to our ChIP-seq result.

\section{Measurement of FGF21, blood lipid and $\beta$-hydroxybutyrate}

FGF21 levels in the serum and culture supernatants of hepatocytes were determined using FGF21 ELISA kits (Antibody \& Immunoassay Services, University of Hong Kong). Nonesteried fatty acids (NEFA) levels were determined using NEFA kits (Westang Bio-Tech co., Ltd, Shanghai, China). Triglycerides and total cholesterol detecting kits were from Shanghai Kehua Bio-Engineering co., Ltd. 
Table 2 Sequence of the primers used for ChIP-qPCR.

\begin{tabular}{|c|c|c|c|}
\hline \multirow[b]{2}{*}{ CREBH promoter } & \multirow[b]{2}{*}{ Antibody } & \multicolumn{2}{|c|}{ Primer sequence $\left(5^{\prime}-3^{\prime}\right)$} \\
\hline & & Forward & Reverse \\
\hline Segment-1 & H3K18ac & 5'-GCTCCATATCCAGCATCTTTG-3' & 5'-CATCACCCACCTGTCACTCC-3' \\
\hline Segment-2 & HNF-4 $\alpha$ & 5'-GCCAAGGGTGAACTGGAACT-3' & 5'-CACAATACAGCAGCGATAAAGG-3' \\
\hline
\end{tabular}

$\beta$-hydroxybutyrate levels were determined using a ketone body assay kit (BioAssay Systems, Hayward, CA, USA).

\section{Statistical analysis}

Student's t-test or two-way ANOVA was used in the statistical analysis. $P<0.05$ was considered statistically significant. Data were expressed as the mean \pm s.E.M. All of the experiments were repeated at least three times independently.

\section{Results}

\section{MS-275 increases FGF21 expression and secretion}

To investigate whether FGF21 is involved in the metabolic benefits of MS-275, primary mouse hepatocytes were isolated and incubated with various concentrations of MS-275 for $8 \mathrm{~h}$. The result showed that MS-275 dose-dependently stimulated FGF21 mRNA expression, with an obvious effect at the concentration of $2.5 \mu \mathrm{mol} / \mathrm{L}$ (Fig. 1A). This was the case for FGF21 protein expression (Fig. 1B). Treatment with $10 \mu \mathrm{mol} / \mathrm{L}$ MS-275 induced FGF21 mRNA expression in a time-dependent manner, with a significant increase at $4 \mathrm{~h}$ (Fig. 1C). A similar trend was observed for FGF21 protein expression in the presence of MS-275 (Fig. 1D). Moreover, FGF21 concentration was obviously raised in the culture supernatant from primary mouse hepatocytes treated with MS-275 for $8 \mathrm{~h}$ (Fig. 1E). To determine the in vivo effect of MS-275, we detected the serum and hepatic FGF21 contents in C57BL/6J mice injected with MS-275. As expected, serum concentration of FGF21 in mice exhibited a significant increase $8 \mathrm{~h}$ after MS-275 injection (Fig. 1F). The induction of FGF21 in the liver of mice also revealed a time-dependent trend, with a marked increase $4 \mathrm{~h}$ after MS-275 injection (Fig. 1G). Our data suggest that MS-275 is a strong inducer of hepatic FGF21.

\section{CREBH mediates MS-275-induced hepatic FGF21 expression}

There are a number of transcription factors involved in the regulation of hepatic FGF21 expression (Mccarty 2015). Thus, we investigated which of transcription factors mediates MS-275-stimulated FGF21 expression in primary mouse hepatocytes. Among transcription factors related to FGF21 expression, the mRNA expression of CREBH revealed the most profound induction by MS-275 (Fig. 2A). $\mathrm{CREBH}$ is emerging to be a key player in the regulation of lipid metabolism via activating FGF21 expression (Lee 2012, Zhang et al. 2012, Wang et al. 2016). Therefore, it is likely that CREBH is involved in MS-275-elicited FGF21 expression. In parallel with induction of FGF21, MS-275 stimulated hepatic CREBH mRNA expression in a doseand time-dependent manner (Fig. 2B and C). Moreover, CREBH expression had been significantly elicited $2 \mathrm{~h}$ after MS-275 treatment, early than the induction of FGF21 (Fig. 2C). Knockdown of CREBH with CREBH-shRNA (Fig. 2D) blocked MS-275-stimulated FGF21 mRNA and protein expressions (Fig. 2E and F). These results suggest

A
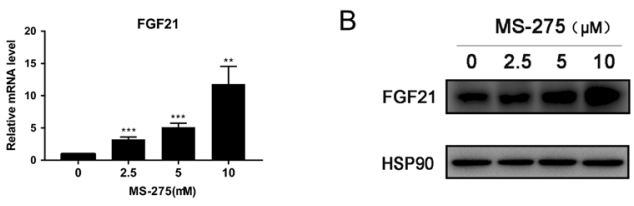

C

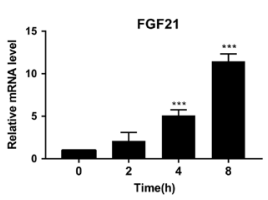

D
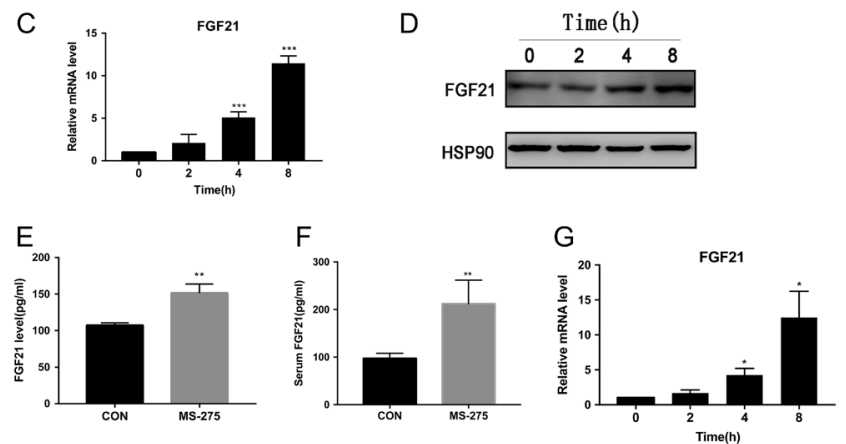

\section{Figure 1}

MS-275 increases FGF21 expression and secretion. (A) FGF21 mRNA expression in primary mouse hepatocytes incubated with various concentrations of MS-275 for 8 h. (B) Representative western blot analysis of FGF21 protein expression in primary mouse hepatocytes incubated with various concentrations of MS-275 for 8 h. FGF21 mRNA (C) and protein (D) expressions in primary mouse hepatocytes treated with $10 \mu \mathrm{M}$ MS-275 for the indicated time. (E) FGF21 concentrations in the culture supernatant from primary mouse hepatocytes treated with and without MS-275 for $8 \mathrm{~h}$. (F) Serum FGF21 concentrations in mice $8 \mathrm{~h}$ after MS-275 injection $(n=5)$. (G) FGF21 mRNA expressions in livers of mice after MS-275 treatment for the indicated time. Data were given as mean \pm S.E.M. for at least three separate measurements. ${ }^{*} P<0.05, * \star P<0.01$, $\star * * P<0.001$ vs control (CON). 
A

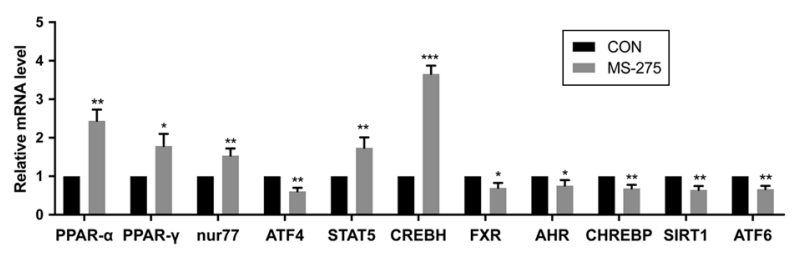

B

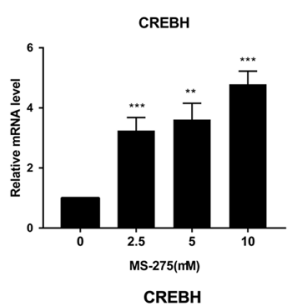

D

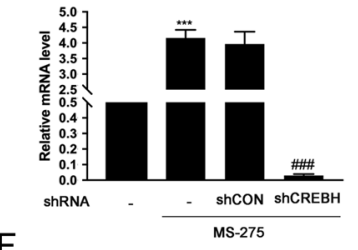

$\mathrm{F}$

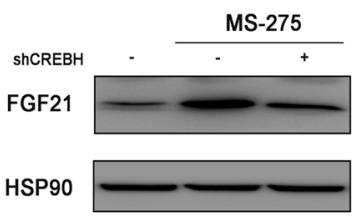

$\mathrm{H}$

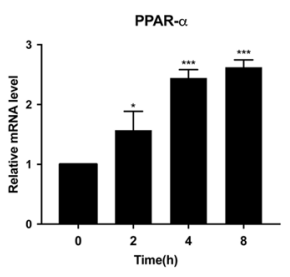

C

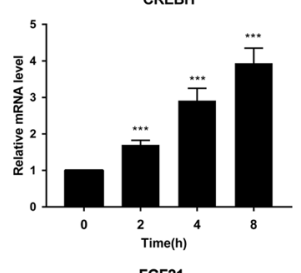

E

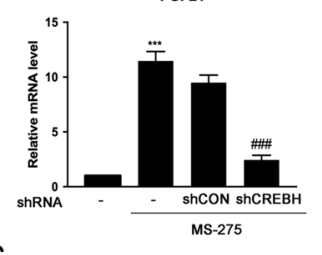

G

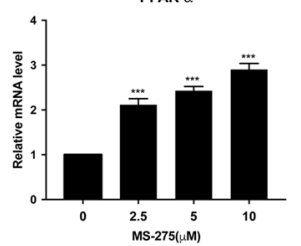

I

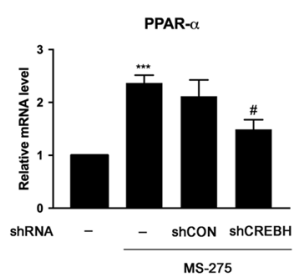

Figure 2

CREBH mediates MS-275-stimulated hepatic FGF21 expression. (A) mRNA expressions of transcription factors in primary mouse hepatocytes treated with MS-275 for $8 \mathrm{~h}$. (B) CREBH mRNA expression in primary mouse hepatocytes treated with various concentrations of MS-275 for $8 \mathrm{~h}$. (C) CREBH mRNA expression in primary mouse hepatocytes treated with $10 \mu \mathrm{M}$ MS-275 for the indicated time. After primary mouse hepatocytes were infected with adenovirus carrying shCREBH or shCON for $24 \mathrm{~h}$, and then treated with $10 \mu \mathrm{M}$ MS-275 for $8 \mathrm{~h}, \mathrm{CREBH}(\mathrm{D}), \mathrm{FGF} 21$ (E) mRNA and FGF21 protein (F) expressions were detected by qRT-PCR and western blot. (G) PPAR- $\alpha$ mRNA expression in primary mouse hepatocytes treated with various concentrations of MS-275 for $8 \mathrm{~h}$. (H) PPAR- $\alpha$ mRNA expression in primary mouse hepatocytes treated with $10 \mu \mathrm{M}$ MS-275 for the indicated time. (I) PPAR- $\alpha$ mRNA expression after shRNA-mediated knockdown of CREBH in primary mouse hepatocytes. Data were given as mean \pm S.E.M. for at least three separate measurements. $* P<0.05$,

$\star \star P<0.01, * \star \star P<0.001$ vs basal; $\# P<0.05, \# \# P<0.001$ vs shCON.

that CREBH mediates MS-275-induced hepatic FGF21 expression.

It has been reported that CREBH interacts with PPAR- $\alpha$ to regulate hepatic FGF21 expression (Kim et al.

2014, Nakagawa et al. 2014). PPAR- $\alpha$ and CREBH mutually activate their expression. CREBH promotes PPAR- $\alpha$ promoter activity in an auto-loop fashion (Nakagawa et al. 2014). In this current study, MS-275 dose- and time-dependently stimulated hepatic PPAR- $\alpha$ (Fig. 2G and $\mathrm{H}$ ). Moreover, silence of CREBH attenuated MS-275stimulated PPAR- $\alpha$ mRNA expression (Fig. 2I). Therefore, it is likely that MS-275 increases FGF21 expression by the interaction of CREBH and PPAR- $\alpha$.

\section{MS-275 activates CREBH expression by H3K18ac-mediated HNF-4 $\alpha$ recruitment}

HDACs regulate gene transcription by compacting chromatin and making it less accessible to transcription factors and activators (Yang \& Seto 2007). Conversely, many histone acetylation sites are concentrated in gene enhancer and promoter regions, which make transcription factors much easier to bind, thus promoting genes transcriptional activation (Wang et al. 2008). MS-275 can strongly suppress HDAC1 and HDAC3 activities. To determine whether MS-275 induces CREBH by increasing histone acetylation levels and transcription factor recruitment in its promoter, we detected the acetylhistone H3 levels in livers of mice and in primary mouse hepatocytes treated with MS-275. As expected, the level of histone $\mathrm{H} 3$ acetylation was strongly elevated by MS-275 (Fig. 3A). We further detected the acetylation levels of three histone $\mathrm{H} 3$ acetylation sites (H3K9ac, H3K18ac and $\mathrm{H} 3 \mathrm{~K} 27 \mathrm{ac}$ ) in primary mouse hepatocytes. Interestingly, their acetylation levels all were significantly increased in the presence of MS-275 (Fig. 3B). To identify the genomic loci related to MS-275 treatment, we performed ChIPseq analyses using anti-H3K18ac. We analyzed H3K18ac genome-wide signals in primary mouse hepatocytes. As expected, MS-275-treated sample exhibited much more H3K18ac peaks compared to control sample (Fig. 3C). There were 14945 peaks in MS-275 treated sample, only 2563 peaks in control sample, which was in accordance with our western blot results (Fig. 3B). Two samples shared 1922 common peaks. Among all 14,945 peaks in MS-275 sample, 4906 peaks were located in promoter regions.

CREBH was one of the genes with different peak enrichment in its promoter region as illustrated in Fig. 3D. We then performed ChIP-qPCR analyses to validate this result using H3K18ac antibody. As shown in Fig. 3E, there existed an increased enrichment in CREBH promoter in primary hepatocytes treated with MS-275, consistent with ChIP-seq results. HNF- $4 \alpha$ is one of the transcription factors of CREBH (Luebke-Wheeler et al. 2008, Park et al. 2016). 
A

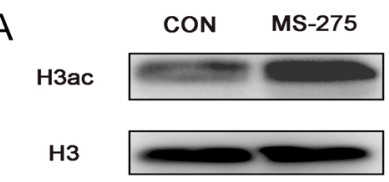

Liver of mouse

B

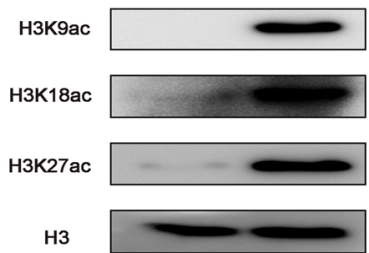

D

$E$
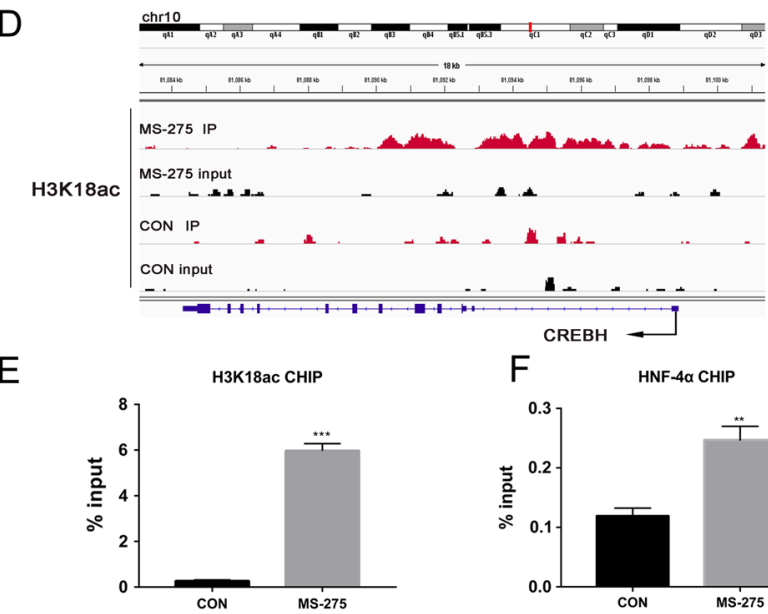

Figure 3

MS-275 activates CREBH by H3K18ac-mediated HNF-4 $\alpha$ recruitment. (A) Representative western blot analysis of total acetyl-histone $\mathrm{H} 3$ (H3ac) in liver of mouse and primary mouse hepatocytes. (B) Representative western blot analysis of three histone $\mathrm{H} 3$ acetylation sites (H3K9ac, $\mathrm{H} 3 \mathrm{~K} 18 \mathrm{ac}$ and H3K27ac) in primary mouse hepatocytes. (C) Comparison of the number of H3K18ac peaks in MS-275-treated and control samples. (D) ChIP-seq result of CREBH using H3K18ac antibody. (E) ChIP-qPCR result using H3K18ac antibody in CREBH promoter. (F) ChIP-qPCR result using HNF- $4 \alpha$ antibody in CREBH promoter. Data were given as mean \pm S.E.M. for at least three separate measurements. $* * P<0.01, * \star * P<0.001$ vs control (CON). A full color version of this figure is available at https://doi. org/10.1530/JME-18-0259.

Our CHIP assay showed that more HNF-4 $\alpha$ were recruited to the CREBH promoter after MS-275 treatment (Fig. 3F), which was covered by H3K18ac peaks (Fig. 3D). Therefore, it is reasonable to suppose that MS-275 increases CREBH production by stimulating H3K18ac-mediated HNF-4 $\alpha$ recruitment.

\section{Effect of MS-275 on energy metabolism in mice}

After MS-275 treatment $(20 \mathrm{mg} / \mathrm{kg}$ i.p., once a day) for 3 days, there were no significant changes of body weight (Fig. 4A) and fasting blood glucose level (Fig. 4B). But a
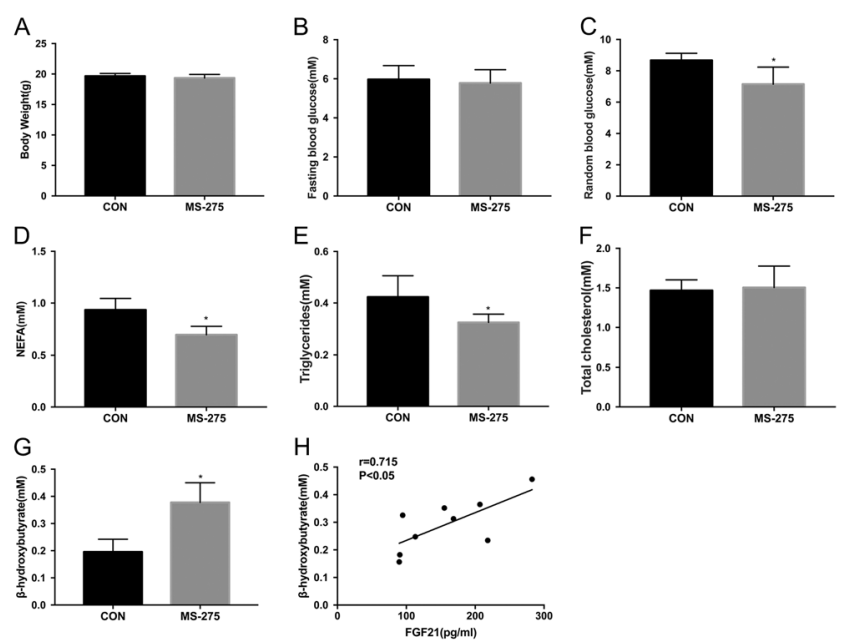

\section{Figure 4}

MS-275 improves metabolic phenotypes in mice. Mice were treated with MS-275 (20 mg/kg i.p.) every day. After 3 days injection, body weight (A), fasting blood glucose $(B)$ and random blood glucose $(C)$ levels were measured. Circulating non-esterified fatty acid (NEFA) (D), triglycerides (E), total cholesterol (F) and $\beta$-hydroxybutyrate $(G)$ concentrations were determined $8 \mathrm{~h}$ after MS-275 injection. $(\mathrm{H})$ Correlations of serum $\beta$-hydroxybutyrate with serum FGF21 level in mice injected with MS-275. Data were given as mean \pm S.E.M. $(n=5)$. ${ }^{\star} P<0.05$ vs control (CON).

reduction of random blood glucose level was observed (Fig. 4C). Circulating NEFA and triglyceride levels were decreased $8 \mathrm{~h}$ after MS-275 injection, but without change for total cholesterol (Fig. 4D, E and F). MS-275 treatment led to an increase in serum $\beta$-hydroxybutyrate level $8 \mathrm{~h}$ after injection (Fig. 4G). Moreover, $\beta$-hydroxybutyrate level exhibited a positive association with serum FGF21 level (Fig. 4H). These data suggest that MS-275 can effectively improve energy metabolism, especially blood lipid profile.

\section{MS-275 increases the expressions of genes involved in fatty acid oxidation and ketogenesis}

Induction of fatty acid oxidation and ketone body production is a major activity of FGF21 (Badman et al. 2009, Potthoff et al. 2012). Thus, we detected whether MS-275 activates the expressions of genes governing lipid and ketone metabolism in vitro and in vivo. PGC- $1 \alpha$, CPT1a and Hmgcs2 mRNA expressions were significantly increased by MS-275 in primary mouse hepatocytes (Fig. 5A). In the livers of mice, MS-275 treatment showed a similar result for the expressions of three genes (Fig. 5B). Moreover, knockdown of CREBH abolished MS-275stimulated PGC-1 $\alpha$, CPT1a and Hmgcs 2 mRNA expressions (Fig. 5C, D and E). These results suggest that FGF21 mediates the regulation of MS-275 on lipid metabolism- 
A

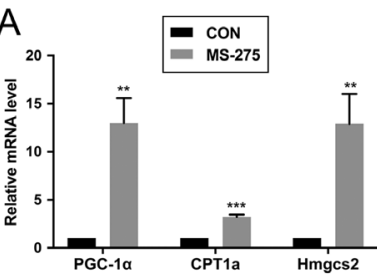

B
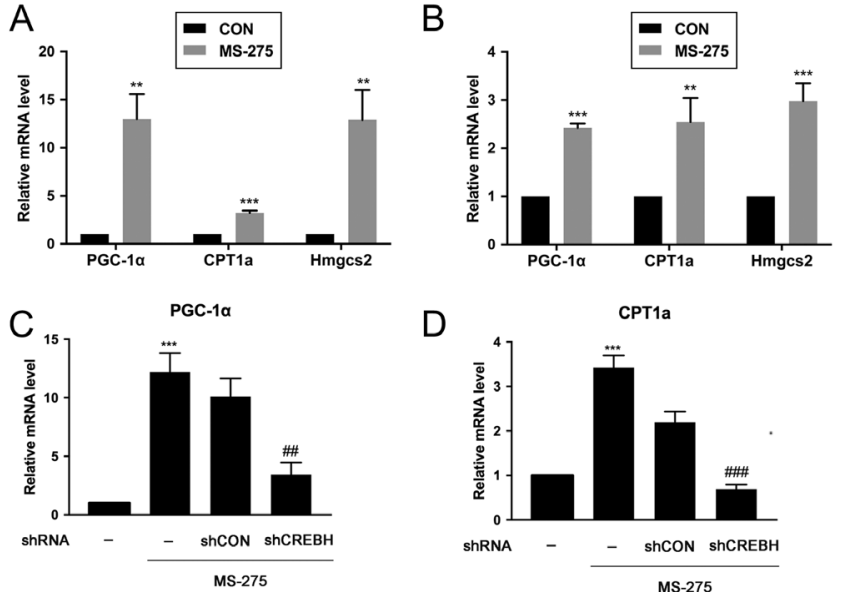

D

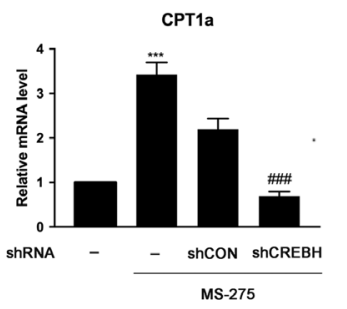

$\mathrm{E}$

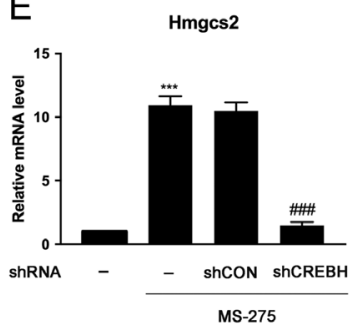

Figure 5

MS-275 activates the expressions of genes involved in fatty acid oxidation and ketogenesis. (A) PGC- $1 \alpha$, CPT1 a and Hmgcs 2 mRNA expressions in primary mouse hepatocytes incubated with MS-275 for $8 \mathrm{~h}$. (B) PGC-1 $\alpha$, CPT1a and Hmgcs2 mRNA expressions in livers of mice $8 \mathrm{~h}$ after MS-275 injection. After primary mouse hepatocytes were infected with adenovirus carrying shCREBH or shCON for $24 \mathrm{~h}$, and then treated with $10 \mu \mathrm{M}$ MS-275 for $8 \mathrm{~h}, \mathrm{PGC}-1 \alpha(\mathrm{C}), \mathrm{CPT} 1 \mathrm{a}(\mathrm{D})$ and Hmgcs2 (E) mRNA expressions were detected by qRT-PCR. (F) Representative western blot analysis for the phosphorylation levels of S6 and S6k in primary mouse hepatocytes after $10 \mu \mathrm{M}$ MS-275 treatment for $2 \mathrm{~h}$. Data were given as mean \pm S.E.M. for at least three separate measurements. ${ }^{*} P<0.01, * * \star P<0.001$ vs control $(\mathrm{CON}) ; \# P<0.01, \# \# P<0.001$ vs shCON.

related gene expressions. It has been demonstrated that FGF21 improves hepatic insulin sensitivity and maintains glucose homeostasis via suppressing mammalian target of rapamycin complex 1 (mTORC1) (Gong et al. 2016). We measured the phosphorylation levels of S6K and S6 two downstream effectors of mTORC1, in primary mouse hepatocytes by western blot. After MS-275 treatment, the phosphorylation levels of S6K and S6 were decreased (Fig. 5F).

\section{Discussion}

Given the beneficial metabolic effect of FGF21 in multiple animal models (Kharitonenkov et al. 2007, Coskun et al. 2008, Xu et al. 2009, Sarruf et al. 2010), the prospect of FGF21 as a drug has steadily progressed. However, the short plasma half-life of FGF21 and its propensity to aggregate in vitro have limited its clinical application (Kharitonenkov et al. 2013). In recent years, multiple laboratories have investigated a series of FGF21 analogs with optimized property (Foltz et al. 2012, Mu et al. 2012, Veniant et al. 2012). Our study shows that MS-275 is a powerful inducer of hepatic FGF21, which may provide a new approach to activate native FGF21 in vivo for metabolic regulation.

PPAR- $\gamma$ agonists induce FGF21 expression in mouse and human hepatocytes (Oishi \& Tomita 2011). Nur77, a transcription factor in the Nur nuclear hormone receptor superfamily (Chang et al. 1989), mediates fasting and glucagon-induced hepatic FGF21 expression in vitro and in vivo (Min et al. 2014). Berberine stimulates hepatic FGF21 expression by promoting transcription of Nur77 (Zhou et al. 2018). STAT5 mediates the effects of growth hormone on hepatic FGF21 expression (Yu et al. 2012). CREBH, a CREB/ATF family member, has been reported to be induced by the acute inflammatory responseinducing factor lipopolysaccharide and proinflammatory cytokines IL-6, IL-1 $\beta$ and TNF- $\alpha$ (Zhang et al. 2006). CREBH induces hepatic FGF21 expression (Lee 2012, Bae et al. 2014, Kim et al. 2014). CREBH-deficient mice exhibit impaired fasting-induced expression of FGF21 (Lee et al. 2011). AHR reduces hepatic FGF21 expression during fasting. The FGF21 promoter contains several putative dioxin response elements (DREs). AHR-ARNT heterodimer binds to a specific DRE that overlaps binding sequences for PPAR- $\alpha$, ChREBP and CREBH (Girer et al. 2016). SIRT1 prevents liver steatosis by inducing FGF21 expression (Li et al. 2014). ATF6 physically interacts with PPAR- $\alpha$, enhances the transcriptional activity of PPAR- $\alpha$ and triggers activation of PPAR- $\alpha$ downstream targets, such as FGF21 (Chen et al. 2016). In this study, CREBH was the most obvious one of upregulated transcription factors induced by MS-275. Therefore, we selected CREBH as the entry point to explore the mechanism underlying MS-275-stimulated FGF21 expression.

PPAR- $\alpha$ is also a key transcription factor involved in the regulation of hepatic FGF21 expression and is activated by fatty acids during both fasting and consumption of a ketogenic diet (Badman et al. 2007, Inagaki et al. 2007). There was a striking absence of hepatic FGF21 mRNA in PPAR- $\alpha$-null mice under chow-fed or fasted conditions (Badman et al. 2007, Inagaki et al. 2007, Lundåsen et al. 2007). It has been reported that CREBH interacts with PPAR- $\alpha$ to regulate hepatic FGF21 expression (Kim et al. 2014, Nakagawa et al. 2014). Our results showed that knockdown of CREBH antagonized MS-275-stimulated hepatic PPAR- $\alpha$ mRNA expression, indicating a possibility 
that the interaction of CREBH and PPAR- $\alpha$ mediates MS-275-stimulated FGF21 expression.

Recently, several HDAC inhibitors have been demonstrated to induce hepatic FGF21 expression. Butyrate increases hepatic production of FGF21 by inhibiting HDAC3 activity in the FGF21 gene promoter to enhance PPAR- $\alpha$ function in the transcriptional activation (Jia 2012). Grape seed procyanidin extract treatment elevated FGF21 gene expression and serum levels in vivo by inhibiting HDAC activity and enhancing PPAR- $\alpha$ expression (Downing et al. 2017). In the present study, MS-275-induced increase in CREBH mRNA expression was more obvious than that in PPAR- $\alpha$. MS-275 elicited hepatic FGF21 expression and secretion in vitro and in vivo. Knockdown of CREBH abrogated MS-275-induced FGF21 expression in primary mouse hepatocytes, suggesting that MS-275-induced hepatic FGF21 production may be largely attributable to CREBH.

It was reported that MS-275 treatment improved glucose tolerance and metabolic profile in $\mathrm{db} / \mathrm{db}$ mice and high fat diet-induced obese mice by promoting oxidative metabolism in skeletal muscle and adipose tissue as well as 'browning' of white adipose tissue (Galmozzi et al. 2013). Treatment of $\mathrm{db} / \mathrm{db}$ mice with MS-275 for over 3 weeks resulted in less accumulation of the lipids in liver, but without significant alteration in hepatic gene expression and mitochondrial content (Galmozzi et al. 2013). However, our results showed that hepatic FGF21 expression was significantly elevated $4 \mathrm{~h}$ after MS-275 treatment in vitro and in vivo. Moreover, expressions of genes related to lipid and ketone metabolism were increased in liver of mice $8 \mathrm{~h}$ after MS-275 injection. Epigenetic changes modulate the accessibility of genes and their cis-regulatory elements to transcriptional complexes, predominantly through histone PTMs (Sims \& Reinberg 2008). The acetylation of lysines is an ubiquitous PTM and is regulated by histone acetyltransferases (HATs) and HDACs, two families of enzymes with opposing activities. HATs catalyze the transfer of an acetyl group to the lysine side chains, neutralize the lysine's positive charge and weaken the interactions between histones and DNA. Histone acetylation leads to a less compact chromatin structure, thereby facilitating DNA access such as transcription factors. On the contrary, HDAC enzymes reverse lysine acetylation, restore the positive charge of the lysine, and potentially stabilizes the local chromatin architecture (Yang \& Seto 2007, Wang et al. 2008, Bannister \& Kouzarides 2011). In our study, MS-275, as a class I-specific HDAC inhibitor, increases H3K18ac signals and recruitment of HNF- $4 \alpha$ to CREBH promoter (Fig. 3), which rapidly induced CREBH expression. Subsequently, FGF21 expression was initiated for the stimulation of ketone body production and fatty acid use as well as the improvement of hepatic insulin sensitivity, which contributed partially to the effects of MS-275 on lipid and glucose metabolism.

In conclusion, we provide evidence that MS-275 induces FGF21 expression in primary mouse hepatocytes, which was attenuated by knockdown of CREBH. MS-275 increases H3K18ac signals for recruiting HNF- $4 \alpha$ to $\mathrm{CREBH}$ promoter. Apparently, MS-275 promotes $\beta$-oxidation and production of ketone bodies via activating CREBHmediated FGF21 expression. Therefore, it is possible that FGF21 mediates the beneficial metabolic effect of MS-275.

\section{Declaration of interest}

The authors declare that there is no conflict of interest that could be perceived as prejudicing the impartiality of the research reported.

\section{Funding}

The present study was funded by grants from the National Natural Science Foundation of China (81670743, 81471030, 81570693, 81770767 and 81800684).

\section{References}

Badman MK, Pissios P, Kennedy AR, Koukos G, Flier JS \& Maratos-Flier E 2007 Hepatic fibroblast growth factor 21 is regulated by PPARalpha and is a key mediator of hepatic lipid metabolism in ketotic states. Cell Metabolism 5 426-437. (https://doi.org/10.1016/j. cmet.2007.05.002)

Badman MK, Koester A, Flier JS, Kharitonenkov A \& Maratos-Flier E 2009 Fibroblast growth factor 21-deficient mice demonstrate impaired adaptation to ketosis. Endocrinology 150 4931-4940. (https://doi.org/10.1210/en.2009-0532)

Bae KH, Kim JG \& Park KG 2014 Transcriptional regulation of fibroblast growth factor 21 expression. Endocrinology and Metabolism 29 105-111. (https://doi.org/10.3803/EnM.2014.29.2.105)

Bannister AJ \& Kouzarides T 2011 Regulation of chromatin by histone modifications. Cell Research 21 381-395. (https://doi.org/10.1038/ cr.2011.22)

Chang C, Kokontis J, Liao SS \& Chang Y 1989 Isolation and characterization of human TR3 receptor: a member of steroid receptor superfamily. Journal of Steroid Biochemistry 34 391-395. (https://doi.org/10.1016/0022-4731(89)90114-3)

Chen X, Zhang F, Gong Q, Cui A, Zhuo S, Hu Z, Han Y, Gao J, Sun Y, Liu Z, et al. 2016 Hepatic ATF6 increases fatty acid oxidation to attenuate hepatic steatosis in mice through peroxisome proliferatoractivated receptor alpha. Diabetes 65 1904-1915. (https://doi. org/10.2337/db15-1637)

Coskun T, Bina HA, Schneider MA, Dunbar JD, Hu CC, Chen Y, Moller DE \& Kharitonenkov A 2008 Fibroblast growth factor 21 corrects obesity in mice. Endocrinology 149 6018-6027. (https://doi. org/10.1210/en.2008-0816)

Downing LE, Ferguson BS, Rodriguez K \& Ricketts ML 2017 A grape seed procyanidin extract inhibits HDAC activity leading to increased 
PPARalpha phosphorylation and target-gene expression. Molecular Nutrition and Food Research 61 1600347. (https://doi.org/10.1002/ mnfr.201600347)

Ferrari A, Fiorino E, Giudici M, Gilardi F, Galmozzi A, Mitro N, Cermenati G, Godio C, Caruso D, De Fabiani E, et al. 2012 Linking epigenetics to lipid metabolism: focus on histone deacetylases. Molecular Membrane Biology 29 257-266. (https://doi.org/10.3109/096 87688.2012.729094)

Ferrari A, Fiorino E, Longo R, Barilla S, Mitro N, Cermenati G, Giudici M, Caruso D, Mai A, Guerrini U, et al. 2017 Attenuation of diet-induced obesity and induction of white fat browning with a chemical inhibitor of histone deacetylases. International Journal of Obesity 41 289-298. (https://doi.org/10.1038/ijo.2016.191)

Fisher FM, Estall JL, Adams AC, Antonellis PJ, Bina HA, Flier JS, Kharitonenkov A, Spiegelman BM \& Maratos-Flier E 2011 Integrated regulation of hepatic metabolism by fibroblast growth factor 21 (FGF21) in vivo. Endocrinology 152 2996-3004. (https://doi. org/10.1210/en.2011-0281)

Foltz IN, Hu S, King C, Wu X, Yang C, Wang W, Weiszmann J, Stevens J, Chen JS, Nuanmanee N, et al. 2012 Treating diabetes and obesity with an FGF21-mimetic antibody activating the betaKlotho/FGFR1c receptor complex. Science Translational Medicine 4 162ra153. (https:// doi.org/10.1126/scitranslmed.3004690)

Galmozzi A, Mitro N, Ferrari A, Gers E, Gilardi F, Godio C, Cermenati G, Gualerzi A, Donetti E, Rotili D, et al. 2013 Inhibition of class I histone deacetylases unveils a mitochondrial signature and enhances oxidative metabolism in skeletal muscle and adipose tissue. Diabetes 62 732-742. (https://doi.org/10.2337/db12-0548)

Girer NG, Murray IA, Omiecinski CJ \& Perdew GH 2016 Hepatic aryl hydrocarbon receptor attenuates fibroblast growth factor 21 expression. Journal of Biological Chemistry 291 15378-15387. (https:// doi.org/10.1074/jbc.M116.715151)

Gong Q, Hu Z, Zhang F, Cui A, Chen X, Jiang H, Gao J, Chen X, Han Y, Liang Q, et al. 2016 Fibroblast growth factor 21 improves hepatic insulin sensitivity by inhibiting mammalian target of rapamycin complex 1 in mice. Hepatology 64 425-438. (https://doi.org/10.1002/ hep.28523)

Guillemot F \& Zimmer C 2011 From cradle to grave: the multiple roles of fibroblast growth factors in neural development. Neuron $\mathbf{7 1}$ 574-588. (https://doi.org/10.1016/j.neuron.2011.08.002)

Inagaki T, Dutchak P, Zhao G, Ding X, Gautron L, Parameswara V, Li Y, Goetz R, Mohammadi M, Esser V, et al. 2007 Endocrine regulation of the fasting response by PPARalpha-mediated induction of fibroblast growth factor 21. Cell Metabolism 5 415-425. (https://doi. org/10.1016/j.cmet.2007.05.003)

Itoh N \& Ornitz DM 2004 Evolution of the Fgf and Fgfr gene families. Trends in Genetics 20 563-569. (https://doi.org/10.1016/j. tig.2004.08.007)

Izumiya Y, Bina HA, Ouchi N, Akasaki Y, Kharitonenkov A \& Walsh K 2008 FGF21 is an Akt-regulated myokine. FEBS Letters $\mathbf{5 8 2}$ 3805-3810. (https://doi.org/10.1016/j.febslet.2008.10.021)

Kharitonenkov A 2009 FGFs and metabolism. Current Opinion in Pharmacology 9 805-810. (https://doi.org/10.1016/j. coph.2009.07.001)

Kharitonenkov A, Shiyanova TL, Koester A, Ford AM, Micanovic R, Galbreath EJ, Sandusky GE, Hammond LJ, Moyers JS, Owens RA, et al. 2005 FGF-21 as a novel metabolic regulator. Journal of Clinical Investigation 115 1627-1635. (https://doi.org/10.1172/JCI23606)

Kharitonenkov A, Wroblewski VJ, Koester A, Chen YF, Clutinger CK, Tigno XT, Hansen BC, Shanafelt AB \& Etgen GJ 2007 The metabolic state of diabetic monkeys is regulated by fibroblast growth factor-21. Endocrinology 148 774-781. (https://doi.org/10.1210/ en.2006-1168)

Kharitonenkov A, Beals JM, Micanovic R, Strifler BA, Rathnachalam R, Wroblewski VJ, Li S, Koester A, Ford AM, Coskun T, et al. 2013 Rational design of a fibroblast growth factor 21-based clinical candidate, LY2405319. PLoS ONE 8 e58575. (https://doi.org/10.1371/ journal.pone.0058575)

Kim H, Mendez R, Zheng Z, Chang L, Cai J, Zhang R \& Zhang K 2014 Liver-enriched transcription factor CREBH interacts with peroxisome proliferator-activated receptor alpha to regulate metabolic hormone FGF21. Endocrinology 155 769-782. (https://doi.org/10.1210/en.20131490)

Lee AH 2012 The role of CREB-H transcription factor in triglyceride metabolism. Current Opinion in Lipidology 23 141-146. (https://doi. org/10.1097/MOL.0b013e3283508fed)

Lee JH, Giannikopoulos P, Duncan SA, Wang J, Johansen CT, Brown JD, Plutzky J, Hegele RA, Glimcher LH \& Lee AH 2011 The transcription factor cyclic AMP-responsive element-binding protein $\mathrm{H}$ regulates triglyceride metabolism. Nature Medicine 17 812-815. (https://doi. org/10.1038/nm.2347)

Li H, Gao Z, Zhang J, Ye X, Xu A, Ye J \& Jia W 2012 Sodium butyrate stimulates expression of fibroblast growth factor 21 in liver by inhibition of histone deacetylase 3. Diabetes 61 797-806. (https:// doi.org/10.2337/db11-0846)

Li Y, Wong K, Giles A, Jiang J, Lee JW, Adams AC, Kharitonenkov A, Yang Q, Gao B, Guarente L, et al. 2014 Hepatic SIRT1 attenuates hepatic steatosis and controls energy balance in mice by inducing fibroblast growth factor 21. Gastroenterology 146 539.e7-549.e7. (https://doi.org/10.1053/j.gastro.2013.10.059)

Luebke-Wheeler J, Zhang K, Battle M, Si-Tayeb K, Garrison W, Chhinder S, Li J, Kaufman RJ \& Duncan SA 2008 Hepatocyte nuclear factor 4alpha is implicated in endoplasmic reticulum stress-induced acute phase response by regulating expression of cyclic adenosine monophosphate responsive element binding protein H. Hepatology 48 1242-1250. (https://doi.org/10.1002/hep.22439)

Lundåsen T, Hunt MC, Nilsson LM, Sanyal S, Angelin B, Alexson SEH \& Rudling M 2007 PPAR $\alpha$ is a key regulator of hepatic FGF21.

Biochemical and Biophysical Research Communications 360 437-440. (https://doi.org/10.1016/j.bbrc.2007.06.068)

Mccarty MF 2015 Practical prospects for boosting hepatic production of the 'pro-longevity' hormone FGF21. Hormone Molecular Biology and Clinical Investigation 30. (https://doi.org/10.1515/hmbci-2015-0057)

Min AK, Bae KH, Jung YA, Choi YK, Kim MJ, Kim JH, Jeon JH, Kim JG, Lee IK \& Park KG 2014 Orphan nuclear receptor Nur77 mediates fasting-induced hepatic fibroblast growth factor 21 expression. Endocrinology 155 2924-2931. (https://doi.org/10.1210/en.2013-1758)

Mu J, Pinkstaff J, Li Z, Skidmore L, Li N, Myler H, Dallas-Yang Q, Putnam AM, Yao J, Bussell S, et al. 2012 FGF21 analogs of sustained action enabled by orthogonal biosynthesis demonstrate enhanced antidiabetic pharmacology in rodents. Diabetes 61 505-512. (https:// doi.org/10.2337/db11-0838)

Muise ES, Azzolina B, Kuo DW, El-Sherbeini M, Tan Y, Yuan X, Mu J, Thompson JR, Berger JP \& Wong KK 2008 Adipose fibroblast growth factor 21 is up-regulated by peroxisome proliferator-activated receptor gamma and altered metabolic states. Molecular Pharmacology 74 403-412. (https://doi.org/10.1124/mol.108.044826)

Nakagawa Y, Satoh A, Yabe S, Furusawa M, Tokushige N, Tezuka H, Mikami M, Iwata W, Shingyouchi A, Matsuzaka T, et al. 2014 Hepatic CREB3L3 controls whole-body energy homeostasis and improves obesity and diabetes. Endocrinology 155 4706-4719. (https://doi. org/10.1210/en.2014-1113)

Nishimura T, Nakatake Y, Konishi M \& Itoh N 2000 Identification of a novel FGF, FGF-21, preferentially expressed in the liver. Biochimica et Biophysica Acta 1492 203-206. (https://doi.org/10.1016/S01674781(00)00067-1)

Oishi K \& Tomita T 2011 Thiazolidinediones are potent inducers of fibroblast growth factor 21 expression in the liver. Biological and Pharmaceutical Bulletin 34 1120-1121. (https://doi.org/10.1248/ bpb.34.1120)

Park JG, Xu X, Cho S \& Lee AH 2016 Loss of transcription factor Crebh accelerates diet-induced atherosclerosis in Ldlr-/- mice. 
Arteriosclerosis, Thrombosis, and Vascular Biology 36 1772-1781. (https://doi.org/10.1161/ATVBAHA.116.307790)

Pham TX \& Lee J 2012 Dietary regulation of histone acetylases and deacetylases for the prevention of metabolic diseases. Nutrients 4 1868-1886. (https://doi.org/10.3390/nu4121868)

Potthoff MJ, Inagaki T, Satapati S, Ding X, He T, Goetz R, Mohammadi M, Finck BN, Mangelsdorf DJ, Kliewer SA, et al. 2009 FGF21 induces PGC-1alpha and regulates carbohydrate and fatty acid metabolism during the adaptive starvation response. PNAS $\mathbf{1 0 6}$ 10853-10858. (https://doi.org/10.1073/pnas.0904187106)

Potthoff MJ, Kliewer SA \& Mangelsdorf DJ 2012 Endocrine fibroblast growth factors 15/19 and 21: from feast to famine. Genes and Development 26 312-324. (https://doi.org/10.1101/gad.184788.111)

Sarruf DA, Thaler JP, Morton GJ, German J, Fischer JD, Ogimoto K \& Schwartz MW 2010 Fibroblast growth factor 21 action in the brain increases energy expenditure and insulin sensitivity in obese rats. Diabetes 59 1817-1824. (https://doi.org/10.2337/db09-1878)

Sims RJ 3rd \& Reinberg D 2008 Is there a code embedded in proteins that is based on post-translational modifications? Nature Reviews: Molecular Cell Biology 9 815-820. (https://doi.org/10.1038/nrm2502)

Veniant MM, Komorowski R, Chen P, Stanislaus S, Winters K, Hager T, Zhou L, Wada R, Hecht R \& Xu J 2012 Long-acting FGF21 has enhanced efficacy in diet-induced obese mice and in obese rhesus monkeys. Endocrinology 153 4192-4203. (https://doi.org/10.1210/ en.2012-1211)

Wang M, Zhao S \& Tan M 2016 bZIP transmembrane transcription factor CREBH: potential role in non-alcoholic fatty liver disease (review). Molecular Medicine Reports 13 1455-1462. (https://doi. org/10.3892/mmr.2015.4749)

Wang Z, Zang C, Rosenfeld JA, Schones DE, Barski A, Cuddapah S, Cui K, Roh TY, Peng W, Zhang MQ, et al. 2008 Combinatorial patterns of histone acetylations and methylations in the human genome. Nature Genetics 40 897-903. (https://doi.org/10.1038/ng.154)
Xu J, Lloyd DJ, Hale C, Stanislaus S, Chen M, Sivits G, Vonderfecht S, Hecht R, Li YS, Lindberg RA, et al. 2009 Fibroblast growth factor 21 reverses hepatic steatosis, increases energy expenditure, and improves insulin sensitivity in diet-induced obese mice. Diabetes $\mathbf{5 8}$ 250-259. (https://doi.org/10.2337/db08-0392)

Yang XJ \& Seto E 2007 HATs and HDACs: from structure, function and regulation to novel strategies for therapy and prevention. Oncogene 26 5310-5318. (https://doi.org/10.1038/sj.onc.1210599)

Yi X, Pashaj A, Xia M \& Moreau R 2013 Reversal of obesity-induced hypertriglyceridemia by (R)- $\alpha$-lipoic acid in ZDF (fa/fa) rats. Biochemical and Biophysical Research Communications 439 390-395. (https://doi.org/10.1016/j.bbrc.2013.08.063)

Yu J, Zhao L, Wang A, Eleswarapu S, Ge X, Chen D \& Jiang H 2012 Growth hormone stimulates transcription of the fibroblast growth factor 21 gene in the liver through the signal transducer and activator of transcription 5. Endocrinology 153 750-758. (https://doi. org/10.1210/en.2011-1591)

Zhang C, Wang G, Zheng Z, Maddipati KR, Zhang X, Dyson G, Williams P, Duncan SA, Kaufman RJ \& Zhang K 2012 Endoplasmic reticulum-tethered transcription factor cAMP responsive element-binding protein, hepatocyte specific, regulates hepatic lipogenesis, fatty acid oxidation, and lipolysis upon metabolic stress in mice. Hepatology 55 1070-1082. (https://doi. org/10.1002/hep.24783)

Zhang K, Shen X, wu J, Sakaki K, Saunders T, Rutkowski DT, Back SH \& Kaufman RJ 2006 Endoplasmic reticulum stress activates cleavage of Crebh to induce a systemic inflammatory response. Cell $\mathbf{1 2 4}$ 587-599. (https://doi.org/10.1016/j.cell.2005.11.040)

Zhou F, Bai M, Zhang Y, Zhu Q, Zhang L, Zhang Q, Wang S, Zhu K, Liu Y, Wang X, et al. 2018 Berberine-induced activation of AMPK increases hepatic FGF21 expression via NUR77. Biochemical and Biophysical Research Communications 495 1936-1941. (https://doi. org/10.1016/j.bbrc.2017.12.070)

Received in final form 26 February 2019

Accepted 20 March 2019

Accepted Preprint published online 20 March 2019 (c) 2019 Society for Endocrinology Published by Bioscientifica Ltd. Printed in Great Britain 